\title{
Current approaches to cervical-cancer screening
}

\section{Citation}

Sawaya, George F., Adalsteinn D. Brown, A. Eugene Washington, and Alan M. Garber. 2001. Current approaches to cervical-cancer screening. New England Journal of Medicine 344, 21:1603-1607.

\section{Published Version}

doi:10.1056/NEJM200105243442107;http://www.nejm.org/doi/full/10.1056/

NEJM200105243442107

\section{Permanent link}

http://nrs.harvard.edu/urn-3:HUL.InstRepos:11563366

\section{Terms of Use}

This article was downloaded from Harvard University's DASH repository, and is made available under the terms and conditions applicable to Other Posted Material, as set forth at http:// nrs.harvard.edu/urn-3:HUL.InstRepos:dash.current.terms-of-use\#LAA

\section{Share Your Story}

The Harvard community has made this article openly available.

Please share how this access benefits you. Submit a story.

\section{Accessibility}




\section{Clinical Practice}

This Journal feature begins with a case vignette highlighting a common clinical problem. Evidence supporting various strategies is then presented, followed by a review of formal guidelines, when they exist. The article ends with the authors' clinical recommendations.

\section{Current Approaches to Cervical-Cancer Screening}

\author{
George F. SaWAya, M.D., \\ AdalsteinN D. Brown, A.B., \\ A. Eugene Washington, M.D., \\ and Alan M. Garber, M.D., Ph.D.
}

A 72-year-old woman has had an annual Papanicolaou (Pap) smear with normal findings (Fig. 1) for the past 30 years. She finds it difficult to undergo pelvic examinations because she has severe arthritis in her hips and vaginal atrophy. She has not been sexually active since the death of her husband 10 years earlier, and she wants to know whether she can stop being screened for cervical neoplasia.

\section{THE CLINICAL PROBLEM}

Although screening for cervical cancer with the Pap smear is one of the most effective preventive interventions that clinicians can provide in their offices, concern about the accuracy of the traditional Pap smear, controversy about the frequency of screening, and the advent of new techniques raise questions about how best to approach screening today. This review considers strategies for optimal cervical-cancer screening, highlights areas of uncertainty, summarizes current guidelines, and provides screening recommendations for the practicing clinician.

\section{STRATEGIES AND EVIDENCE}

Dramatic reductions in the incidence of squamouscell cancers of the cervix have accompanied the widespread use of Pap tests in the United States. ${ }^{1}$ All U.S. women who have a cervix and who are or who have

From the Department of Obstetrics, Gynecology and Reproductive Sciences, University of California, San Francisco, San Francisco (G.F.S., A.E.W.); the University of California, San Francisco-Stanford Evidence-based Practice Center, San Francisco (G.F.S., A.E.W., A.M.G.); the Department of Health Administration, University of Toronto, Toronto (A.D.B.); and the Veterans Affairs Palo Alto Health Care System and Center for Primary Care and Outcomes Research, Stanford University, Palo Alto, Calif. (A.M.G.).

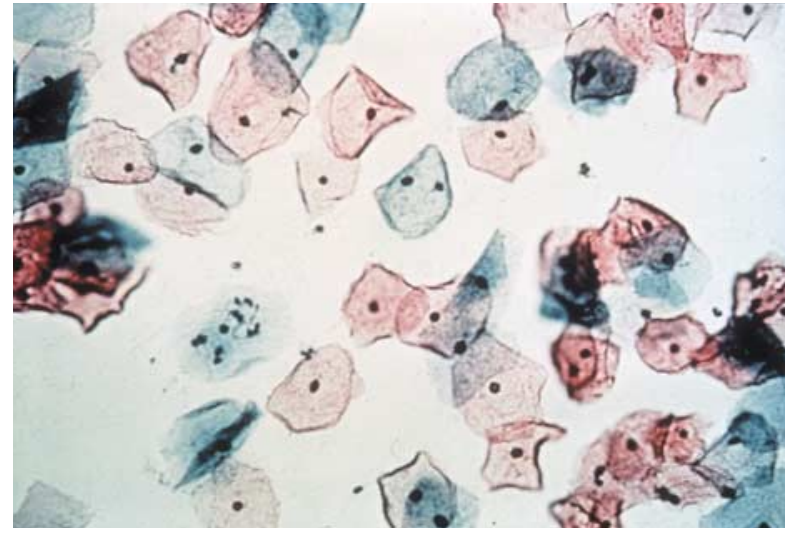

Figure 1. Normal Pap Smear (Papanicolaou Stain, $\times 20$ ).

Photomicrograph provided courtesy of Dr. Douglas K. Hanks, University of California, San Francisco.

been sexually active - a group that numbers approximately 87 million - are encouraged to participate in screening programs.

Cervical cancer is thought to be the long-delayed consequence of sexually transmitted human papillomavirus (HPV) infection. ${ }^{2}$ In a small minority of women exposed to HPV, the infection progresses to asymptomatic high-grade preinvasive dysplastic lesions and, ultimately, to invasive cancer. An estimated 40 percent of untreated high-grade lesions will progress to invasive cancer over an average of 10 years. ${ }^{3}$ Periodic screening offers many opportunities to discover and treat preinvasive lesions (Fig. 2). Consequently, even though HPV infection is common, with screening a U.S. woman's lifetime risk of cervical cancer is estimated to be only 0.8 percent. $^{3}$

Further reductions in the approximately 12,800 cases of cervical cancer that are diagnosed each year in the United States may be achieved by a variety of means. Given that about half of the U.S. women in whom cervical cancer develops have never been screened, ${ }^{4}$ efforts aimed at encouraging women to be screened hold the most promise for reducing the incidence of and mortality from cervical cancer. Although it is difficult to increase the rate of Pap testing, particularly among women who seldom visit clinicians, practitioners can help by offering screening to women who are being seen for other reasons. For example, in one study of a large prepaid health plan with few barriers to access, most of the women with invasive cervical cancer had not had a Pap smear in the three years before their diagnosis, even though 


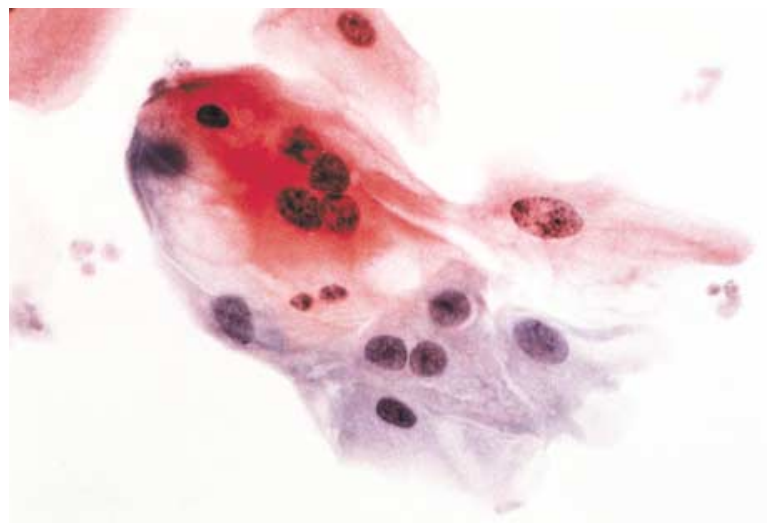

A
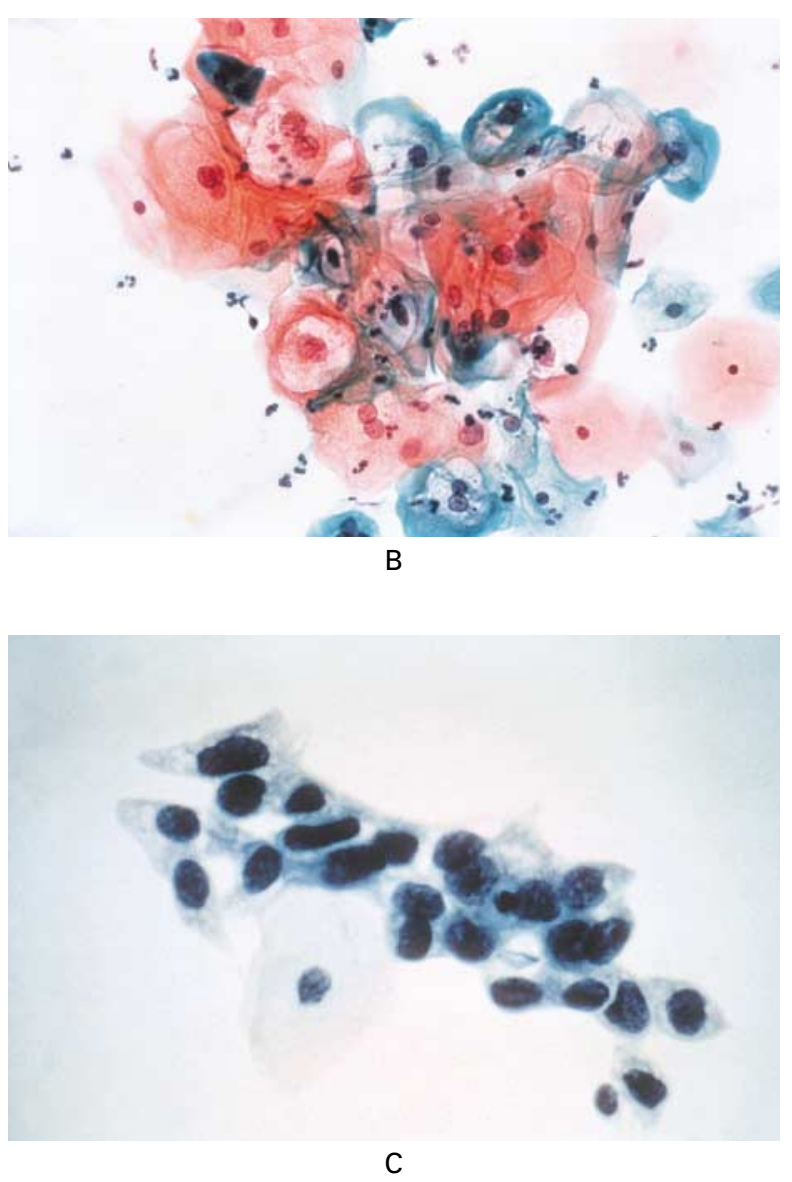

Figure 2. Abnormal Pap-Smear Findings.

Panel A shows atypical squamous cells of undetermined significance (Papanicolaou stain, $\times 40$ ). Panel B shows a low-grade squamous intraepithelial lesion (Papanicolaou stain, $\times 40$ ). Panel $\mathrm{C}$ shows a high-grade squamous intraepithelial lesion (Papanicolaou stain, $\times 40$ ). Photomicrographs provided courtesy of Dr. Douglas K. Hanks, University of California, San Francisco.
75 percent had been seen in primary care outpatient clinics during that period. 5

Another strategy to reduce the incidence of cancer is to minimize errors related to the sampling technique itself and the interpretation of the findings. These errors account for approximately one fourth of all cases of invasive cervical cancer. ${ }^{6-8}$ Clinicians can decrease the likelihood of sampling error - the failure to obtain and transfer dysplastic cells to the slide - by choosing a method of cell collection that will obtain adequate samples from the endocervical canal. ${ }^{9}$ In a systematic review of studies that focused on histologically confirmed high-grade cervical dysplasia, ${ }^{10}$ the use of a spatula in combination with an endocervical brush appeared to increase the rate of detection of disease without increasing the rate of false positive findings.

\section{AREAS OF UNCERTAINTY}

Although it is widely accepted that screening for cervical neoplasia saves lives, there is no consensus about when screening should start, how long it should continue, the frequency of screening, or the optimal screening technique. The information needed to make informed decisions is, in many respects, incomplete.

\section{When to Begin Screening}

Screening is unlikely to be beneficial before a woman becomes sexually active and thus at risk for exposure to HPV. Concern about the potential inaccuracy of a woman's reported sexual history, however, has prompted recommendations that screening begin at the age of 18 years, regardless of the woman's reported sexual activity. Determining the optimal age to begin screening is important for several reasons. Acute HPV infection is common soon after the initiation of sexual activity, and most infections clear within 24 months. ${ }^{11,12}$ These infections can cause cytologic abnormalities, the majority of which are not associated with high-grade cervical dysplasia. These abnormal findings lead to further diagnostic evaluations.

Treatment of dysplastic lesions with cryotherapy, the loop electrosurgical excision procedure (known as LEEP), laser ablation, and cone biopsy is common, though data are lacking from large-scale studies on the effect that these interventions may have on future fertility and pregnancy outcomes. Moreover, false positive results can cause patients needless anxiety and concern. ${ }^{13}$ The transient nature of most HPV infections, the long preinvasive phase of dysplasia, ${ }^{3}$ and the potential harm that can result from overdiagnosis and overtreatment argue against introducing screening too soon after the initiation of sexual activity. Research is needed to quantify the reduction in the risk of cancer, as well as the harm, that might result from early initiation of screening.

Many European countries with low rates of cervical cancer do not screen adolescents and young, sexual- 
ly active women. For example, the National Health Service of the United Kingdom recommends that screening begin at the age of 21 years, and the Finnish Cancer Organization recommends beginning screening at the age of 30 years.

\section{When to End Screening}

Although most cases of cervical cancer and deaths from cervical cancer occur in women older than $\mathbf{5 0}$ years of age, most of these women have not been screened adequately. The very low incidence of new cases of cervical disease among older women who have no evidence of recent disease and who have been screened regularly and properly ${ }^{14-17}$ argues against continued screening in this population. Furthermore, with advancing age or the presence of serious coexisting conditions, the potential benefits of screening are offset by the likelihood that a woman will die of another cause or will suffer needlessly as a consequence of a false positive result. ${ }^{15}$ Older women who have undergone a total hysterectomy for diseases other than cervical neoplasia are not at risk for cervical cancer and should not be screened. ${ }^{18}$ Practitioners should be aware, however, that some women may have undergone a supracervical hysterectomy in which the cervix is retained.

\section{Frequency of Screening}

Repeated screening after a normal result can detect abnormalities missed on earlier tests, as well as abnormalities that have developed since the first test. The frequency of screening should therefore depend on the sensitivity of the screening test and the rate of progression of preinvasive disease. ${ }^{19}$ An individual woman's risk factors should have little effect on the frequency of screening unless these factors are associated with low test sensitivity (as may be the case if a woman has had only one prior test with normal results, which may have missed disease) or an accelerated rate of progression of preinvasive disease (as may be the case in an immunocompromised woman).

Although the absolute risk of the development of invasive squamous-cell cancer as a consequence of a false negative test is small (occurring in fewer than 5 women per 100,000 per year), annual screening has been common practice in the United States for many years. There is little evidence to suggest, however, that outcomes are substantially better with annual screening than with biennial ${ }^{20}$ or triennial ${ }^{21}$ screening. Although a single conventional Pap test may have a relatively low sensitivity, ${ }^{3}$ the cumulative sensitivity of several tests performed within a relatively short time should be high. No cytologic test, however, is likely to detect cervical neoplasia in the unknown but small percentage of women with disease in whom abnormal cells are not exfoliated.

High-grade dysplasia or rapidly progressive cervical disease is unlikely to be overlooked or to develop within three years after a normal examination in immunocompetent women who have had multiple normal smears. Further research is needed to determine the optimal number of normal results after which the interval between tests can safely be lengthened. Because the preinvasive stage of disease may be briefer in women who are immunocompromised, women who are receiving immunosuppressive therapy or those who are infected with the human immunodeficiency virus (HIV) are thought to be poor candidates for less frequent screening. In the case of women with HIV infection, a pattern of annual testing after two tests performed six months apart have had normal results has been shown to be cost effective. ${ }^{22}$

\section{Newer Methods of Screening}

Litigation and media coverage have led to broad public awareness of the imperfect sensitivity of Pap smears. Several new techniques are being promoted that increase sensitivity by reducing errors in sampling and interpretation. Clinicians should be aware that all such techniques may also decrease specificity: more abnormalities may be discovered at the cost of an increase in the number of healthy women who are unnecessarily alarmed by a false report of an abnormality and who subsequently undergo needless diagnostic procedures and interventions.

Among the most commonly used innovations in cervical-cancer screening is liquid-based cytologic collection and analysis. The literature on this technique, which has been approved by the Food and Drug Administration for primary screening, is voluminous, and three systematic reviews have been published recently. $23-25$ Two found evidence of improved sensitivity, 23,24 and one found evidence of decreased specificity. ${ }^{23}$ All three concluded that too few studies of sufficient methodologic rigor have been performed to indicate the true accuracy of liquid-based cytologic analysis, with the chief concern being inadequate data on specificity.

Reevaluation of conventional smears initially interpreted as negative, either on the basis of a manual review or with the assistance of a computerized technique, can also improve the sensitivity of testing by decreasing errors in the interpretation of results. Liquid-based preparations and computerized rescreening increase both the sensitivity and the costs of screening for cervical cancer. The cost effectiveness of these methods depends on the manner in which they are used. They are most likely to be cost effective if they are used as an adjunct to a program in which screening is done every three years; the cost per year of life saved is very high if they are used to improve the sensitivity of annual screening.

Liquid-based cytologic collection and analysis and computerized rescreening are most likely more cost effective when they are used by laboratories where tests have relatively poor sensitivity. They are unlikely to 
be cost effective when they are adopted by laboratories that already interpret Pap smears with a high degree of accuracy. ${ }^{26}$ Cost-effectiveness models to date have assumed that the specificity of new techniques is no different from that of older approaches; if liquid-based cytologic collection and analysis have a lower specificity, for example, the cost effectiveness will be adversely affected. ${ }^{27}$

The advent of newer methods of HPV detection has led to increasing interest in the role of testing for this virus in screening. One of the most promising uses of HPV testing is to determine which women with low-grade cytologic abnormalities require colposcopic evaluation. Preliminary results of a randomized trial designed to clarify the roles of HPV testing, repeated Pap testing, and colposcopy in the evaluation of low-grade abnormalities indicate that HPV testing can help identify which women with a single smear that shows atypical squamous cells of undetermined significance should undergo colposcopy, ${ }^{28}$ but that it is not as helpful in women with smears that show low-grade squamous intraepithelial lesions. ${ }^{29}$ Less information is available for other uses of HPV testing, and important questions remain about the implications of a positive HPV test. There is little evidence to support the use of any specific management strategy for a woman with no detectable cervical disease who is found to have a high-risk type of HPV. At present, the role of HPV testing as an adjunct to or substitute for established and effective cytologic screening programs has not been evaluated adequately. ${ }^{30}$

\section{GUIDELINES}

The American Cancer Society ${ }^{31}$ and the American College of Obstetricians and Gynecologists 32 recommend that screening begin at the age of 18 years, regardless of whether a woman is sexually active. The American Academy of Family Physicians, the Canadian Task Force on Preventive Health Care, the American College of Preventive Medicine, and the U.S. Preventive Services Task Force support the view that screening should be initiated when women become sexually active. ${ }^{33}$ The latter two recommend beginning screening at the age of 18 years if a woman's sexual history is unknown or if the reported history is thought to be unreliable.

Most groups do not specify an age at which screening may end, though the U.S. Preventive Services Task Force recommends discontinuing screening in women over the age of 65 years who have been screened regularly and who have had consistently normal results. The Canadian Task Force recommends that such women should stop being screened at the age of 69 years. The American College of Preventive Medicine recommends that screening be stopped at the age of 65 years in women who have undergone regular screening and who have had no abnormal re- sults within the previous nine years. All guidelines state that the interval between tests may be extended to as long as three years if two or three consecutive tests have been normal. Some guidelines, however, indicate that continued annual screening be considered in women with certain risk factors, such as a first occurrence of sexual intercourse at an age of less than 18 years, multiple sexual partners or a consort with multiple sexual partners, smoking, or low socioeconomic status.

\section{CONCLUSIONS AND RECOMMENDATIONS}

The Pap smear remains the archetype of a successful preventive intervention. Some strategies used to increase the sensitivity of screening - such as newer methods of collection and interpretation, as well as more frequent testing - may, however, also increase the false positive rate. Clinicians should consider the costs and consequences of false positive tests along with the benefits that result from heightened sensitivity.

Women obtain health care information from diverse sources, including the mainstream press and directto-consumer marketing. They may perceive recommendations for less frequent screening, the policy of discontinuing screening after a certain age, and the slow rate of adoption of new screening methods as attempts to save money at their expense, even when respected professional groups are the source of the recommendations. Women who have actively participated in screening programs and who have had no evidence of cervical disease should be informed that their absolute risk of undiagnosed but clinically important cervical disease is very small and that any additional benefits of frequent screening with conventional smears and more sensitive techniques are likely to be small. Evidence concerning technological advances in screening, such as liquid-based cytologic collection and analysis and HPV testing, accrues rapidly and will need to be continually updated and summarized. In the future, combinations of techniques and more focused screening strategies hold the promise of making screening more effective, safer, and less costly.

In summary, practitioners should seek out and offer screening to women at risk for cervical cancer who have not been screened within at least the preceding three years. Until better data become available, screening should begin after the initiation of sexual activity or the age of 18 years if information about a woman's sexual history is unknown or is deemed unreliable. Regularly screened women who are 65 years of age or older and who have a documented history of consecutive normal Pap smears and no evidence of recent cervical dysplasia gain little from continued screening, especially if they are no longer sexually active. This is the case for the woman described in the clinical vignette. Women who have undergone a total hysterectomy for diseases other than cervical neoplasia 
should no longer be screened. In the case of immunocompetent women who have had multiple consecutive normal Pap smears, clinically important cervical disease is unlikely to develop within a period of three years and the interval between tests could probably be safely extended to as long as three years. Clinicians should remain up to date about the benefits and harms associated with various screening strategies so that they can provide women with accurate and complete information to facilitate fully informed decision making.

\section{REFERENCES}

1. Ries LAG, Kosary CL, Hankey BF, Miller BA, Clegg L, Edwards BK. SEER cancer statistics review, 1973-1996. Bethesda, Md.: National Cancer Institute, 1999

2. Walboomers JM, Jacobs MV, Manos MM, et al. Human papillomavirus is a necessary cause of invasive cervical cancer worldwide. J Pathol 1999; 189:12-9.

3. Evaluation of Cervical Cytology: evidence report/technology assessment. No. 5. Rockville, Md.: Agency for Health Care Policy and Research, 1999.

4. Cervical cancer. NIH consensus statement. Vol. 14. No. 1. Bethesda, Md.: Office of Medical Applications of Research, April 1996:1-38.

5. Kinney W, Sung HY, Kearney KA, Miller M, Sawaya G, Hiatt RA.

Missed opportunities for cervical cancer screening of HMO members de veloping invasive cervical cancer (ICC). Gynecol Oncol 1998;71:428-30. 6. Sawaya GF, Grimes DA. New technologies in cervical cytology screening: a word of caution. Obstet Gynecol 1999;94:307-10

7. Sung HY, Kearney KA, Miller M, Kinney W, Sawaya GF, Hiatt RA. Papanicolaou smear history and diagnosis of invasive cervical carcinoma among members of a large prepaid health plan. Cancer $2000 ; 88: 2283-9$. 8. Janerich DT, Hadjimichael O, Schwartz PE, et al. The screening histories of women with invasive cervical cancer, Connecticut. Am J Public Health $1995 ; 85: 791-4$

9. Martin-Hirsch P, Lilford R, Jarvis G, Kitchener HC. Efficacy of cervical-smear collection devices: a systematic review and meta-analysis. Lancet 1999;354:1763-70. [Erratum, Lancet 2000;355:414.]

10. Sawaya GF, Washington AE. Cervical cancer screening: which techniques should be used and why? Clin Obstet Gynecol 1999;42:922-38.

11. Ho GYF, Bierman R, Beardsley L, Chang CJ, Burk RD. Natural history of cervicovaginal papillomavirus infection in young women. N Engl J Med 1998;338:423-8.

12. Moscicki AB, Shiboski S, Broering J, et al. The natural history of human papillomavirus infection as measured by repeated DNA testing in adolescent and young women. J Pediatr 1998;132:277-84.

13. Bell S, Porter M, Kitchener H, Fraser C, Fisher P, Mann E. Psychological response to cervical screening. Prev Med 1995;24:610-6.

14. Sawaya GF, Kerlikowske K, Lee NC, Gildengorin G, Washington AE. Frequency of cervical smear abnormalities within 3 years of normal cytology. Obstet Gynecol 2000;96:219-23.

15. Sawaya GF, Grady D, Kerlikowske K, et al. The positive predictive value of cervical smears in previously screened postmenopausal women: the Heart and Estrogen/progestin Replacement Study (HERS). Ann Intern Med 2000;133:942-50.
16. Van Wijngaarden WJ, Duncan ID. Rationale for stopping cervical screening in women over 50. BMJ 1993;306:967-71. [Erratum, BM] 1993;306:1373.]

17. Cruickshank ME, Angus V, Kelly M, McPhee S, Kitchener HC. The case for stopping cervical screening at age 50. Br J Obstet Gynaecol 1997; 104:586-9.

18. Pearce KF, Haefner HK, Sarwar SF, Nolan TE. Cytopathological findings on vaginal Papanicolaou smears after hysterectomy for benign gynecologic disease. N Engl J Med 1996;335:1559-62.

19. Frame PS, Frame JS. Determinants of cancer screening frequency: the example of screening for cervical cancer. J Am Board Fam Pract 1998;11: 87-95.

20. Shy K, Chu J, Mandelson M, Greer B, Figge D. Papanicolaou smear screening interval and risk of cervical cancer. Obstet Gynecol 1989;74:838 43.

21. IARC Working Group on Evaluation of Cervical Cancer Screening Programmes. Screening for squamous cervical cancer: duration of low risk after negative results of cervical cytology and its implication for screening policies. BMJ 1986;293:659-64

22. Goldie SJ, Weinstein MC, Kuntz KM, Freedberg KA. The costs, clinical benefits, and cost-effectiveness of screening for cervical cancer in HIV infected women. Ann Intern Med 1999;130:97-107.

23. Nanda K, McCrory DC, Myers ER, et al. Accuracy of the Papanicolaou test in screening for and follow-up of cervical cytologic abnormalities: a systematic review. Ann Intern Med 2000;132:810-9.

24. Payne N, Chilcott J, McGoogan E. Liquid-based cytology in cervical screening. Sheffield, England: University of Sheffield School of Health and Related Research, 2000.

25. Broadstock M. Effectiveness and cost effectiveness of automated and semiautomated cervical screening devices: a systematic review. NZHTA report. Vol. 3. Christchurch, New Zealand: Clearing House for Health Outcomes and Health Technology Assessment, 2000.

26. Brown $\mathrm{AD}$, Garber AM. Cost-effectiveness of 3 methods to enhance the sensitivity of Papanicolaou testing. JAMA 1999;281:347-53.

27. Myers ER, McCrory DC, Subramanian S, et al. Setting the target for a better cervical screening test: characteristics of a cost-effective test for cervical neoplasia screening. Obstet Gynecol 2000;96:645-52.

28. Solomon D, Schiffman M, Tarone R. Comparison of three management strategies for patients with atypical squamous cells of undetermined significance: baseline results from a randomized trial. J Natl Cancer Inst 2001;93:293-9.

29. The Atypical Squamous Cells of Undetermined Significance/LowGrade Squamous Intraepithelial Lesions Triage Study (ALTS) Group. Human papillomavirus testing for triage of women with cytologic evidence of low-grade squamous intraepithelial lesions: baseline data from a randomized trial. J Natl Cancer Inst 2000;92:397-402.

30. Cain JM, Howett MK. Preventing cervical cancer. Science 2000;288 1753-5.

31. Shingleton HM, Patrick RL, Johnston WW, Smith RA. The current status of the Papanicolaou smear. CA Cancer J Clin 1995;45:305-20.

32. Routine cancer screening. ACOG committee opinion no. 247. Washington, D.C.: American College of Obstetricians and Gynecologists, 2000 33. National Guideline Clearinghouse. Washington, D.C.: National Guide line Clearinghouse, 2001. (See http://www.guideline.gov.) (See NAPS document no. 05594 for 6 pages, c/o Microfiche Publications, 248 Hempstead Tpke., West Hempstead, NY 11552.

Copyright (C) 2001 Massachusetts Medical Society. 